\title{
BENTUK LAGU MARS FKIP UNIVERSITAS PGRI PALEMBANG IRINGAN MUSIK FORMAT ORKESTRA Silo Siswanto ${ }^{1)}$
}

\author{
${ }^{1)}$ Program Studi Sendratasik Universitas PGRI Palembang \\ Jl. Jend. Ahmad Yani, Lorong Gotong Royong No.9/10 Palembang Kode pos 30263 \\ Email:silo.guitar@Gmail.com,
}

\begin{abstract}
The motto of PGRI Palembang University is that the campus advances with quality. Then a need for faculties to make a stragi in providing encouragement and motivation to the academic community to carry out the tri dharma of higher education. (FKIP) Palembang PGRI University through its highest leadership in the faculty gave a letter of assignment to work on the Mars song FKIP PGRI Palembang University to one of the music art lecturers in the performing arts education study program named Silo Siswanto, M.Sn. Then the Mars song was finished on July 23, 2018 and was launched on July 31, 2018 in the FKIP University of Palembang PGIP judicial event held at the Science Center building at the PGRI University in Palembang. Regarding the form in the Mars song, of course, this song has pieces of melody that are often known by the term phrases or musical sentences that make up the song. while the accompaniment music is arranged in an orchestra format. The formulation of the problem. (1) What is the form of Mars FKIP University PGRI Palembang song. (2) How is the accompaniment of Mars FKIP Palembang PGRI University music with orchestra format. The results of the discussion FKIP march song has a poly metric musical form where the antecedent phrase and consequent phrase do not have the same number of bars for example period $C$ has 9 bars consisting of the phrase $d 4$ bars and the phrase e 5 bars.
\end{abstract}

Keywords: Song Form, Mars Song, Orchestra

\begin{abstract}
ABSTRAK
Motto Universitas PGRI Palembang yakni kampus melaju dengan mutu. Maka suatu kebutuhan bagi fakultas-fakultas membuat suatu stragi dalam memberikan dorongan dan motovasi kepada civitas akademika untuk melaksanakan tri dharma perguruan tinggi. (FKIP) Universitas PGRI Palembang melalui pimpinan tertingginya di fakultas memberikan surat tugas untuk penggarapan lagu Mars FKIP Univesitas PGRI Palembang kepada salah satu dosen seni musik di prodi pendidikan seni pertunjukan bernama Silo Siswanto, M.Sn. Kemudian lagu Mars tersebut selesai dibuat tanggal 23 juli 2018 dan di launching pada tanggal 31 juli 2018 dalam acara yudisium FKIP Universitas PGRI Palembang bertempat di gedung Science Center Universitas PGRI Palembang. Mengenai bentuk dalam lagu Mars tersebut, tentunya lagu ini memiliki potongan-potongan melodi yang sering dikenal dengan istilah frase atau kalimat musik yang membentuk lagu tersebut. sedangkan musik iringannya diarransemen dengan format orkestra. Adapun rumusan masalahnya. (1) Bagaimana bentuk lagu Mars FKIP Universitas PGRI Palembang. (2) Bagaimana musik iringan lagu Mars FKIP Universitas PGRI Palembang dengan format orchestra. Hasil pembahasan Lagu mars FKIP memiliki bentuk musik poli metrik dimana frase antecedent dan frase consequent tidak memiliki jumlah birama yang sama misalnya periode $\mathrm{C}$ memiliki 9 birama yang terdiri dari frase d 4 birama dan frase e 5 birama.
\end{abstract}

Keywords: Bentuk Lagu, Lagu Mars, Orkestra 


\section{Pendahuluan}

Lagu sama halnya dengan nyanyian dan dapat diartikan melodi pokok, juga berarti karya musik. sebuah karya musik untuk dinyanyikan atau dimainkan dengan pola dan bentuk tertentu (Banoe, 2003 : 233). Mengenai bentuk dalam karya musik menjadi pilihan bagi komposer untuk menentukan hasil karyanya yang akan disusun dalam garapannya, sehingga karya musik tersebut atau dengan nama lain lagu yang diciptakan akan dapat dideskripsikan bagian-bagian terpendek pada frase musiknya.

Sedangkan lagu Mars memiliki makna komposisi musik dengan irama teratur dan kuat. Musik jenis ini secara khusus diciptakan untuk meningkatkan keteraturan dalam berbaris sebuah kelompok besar, terutama barisan tentara, dan paling sering dimainkan oleh korps musik militer. Lagu Mars dapat ditulis dalam birama genap 2/4, 4/4, tetapi kadang-kadang dalam birama 6/8, atau 2 (genap) $\times 3 / 8$ dengan tempo cepat, (Simanungkalit, dalam karyawanto 2008: 8).

Berangkat dari pernyataan Simanungkalit tersebut hal ini senada dengan motto Universitas PGRI Palembang yakni kampus melaju dengan mutu. Maka suatu kebutuhan bagi fakultas-fakultas membuat suatu stragi dalam memberikan dorongan dan motovasi kepada civitas akademika untuk melaksanakan tri dharma perguruan tinggi. dalam hal ini Fakultas Keguruan dan Ilmu Pendidikan (FKIP) Universitas PGRI Palembang melalui pimpinan tertingginya di fakultas memberikan surat tugas untuk penggarapan lagu Mars FKIP Univesitas PGRI Palembang kepada salah satu dosen seni musik di prodi pendidikan seni pertunjukan yakni bernama Silo Siswanto, M.Sn. Kemudian lagu Mars tersebut selesai dibuat pada tanggal 23 juli 2018 dan di launching pada tanggal 31 juli 2018 dalam acara yudisium FKIP Universitas PGRI Palembang bertempat di gedung Science Center Universitas PGRI Palembang.

Lagu Mars FKIP Universitas PGRI Palembang sampai sekarang terus dibawakan oleh mahasiswa dari berbagai prodi dari Fakultas Keguruan dan Ilmu Pendidikan setiap acara yudisium FKIP Universitas PGRI Palembang. Lagu Mars tersebut memiliki bentuk dan struktur musik dengan arransement iringan musik format orchestra.

Mengenai bentuk dalam lagu Mars tersebut, tentunya lagu ini memiliki potongan-potongan melodi yang sering dikenal dengan istilah frase atau kalimat musik yang membentuk lagu tersebut. sedangkan musik iringannya diarransement dengan format orkestra. Dalam hal ini arranger memiliki kemampuan yang khusus untuk dapat membuat mengarrasement iringan musiknya dengan format orchestra. Kemampuan yang khusus dapat dipahami seorang arrenger agar dapat mengarransement format orkestra yang sedemikian rumitnya bahwa format orchestra dalam arransemet musik, arrenger tidak hanya memahami berbagai register nada pada setiap instrument melainkan juga harus mempertimbangkan orkestrasinya dalam pemilihan warna bunyi atau tone colour pada melodi iringan yang akan dimainkan pada setiap alat musik.

Berdasarkan uraian di atas maka diperlukanlah pemikiran yang khusus dan keilmuan yang khususpula untuk dapat menganalis bantuk karya musik tersebut yang berupa lagu Mars dengan iringan format orkestra. Sehingga penelitian ini menitikberatkan pada fokuspenelitian yakni melihat bentuk lagu nya dengan iringan musik format orchestra.

Adapun persoalan yang hedak diungkap terurai pada rumusan masalah. (1) Bagaimana bentuk lagu Mars FKIP Universitas PGRI Palembang. (2) Bagaimana musik iringan lagu Mars FKIP Universitas PGRI Palembang dengan format orchestra.

Tujuan kegiatan penelitian ini secara umum yakni mendapatkan gambaran umum tentang bentuk lagu Mars FKIP Universitas PGRI Palembang, secara khusus untuk membeda lagu tersebut perkalimat musik dalam tiap-tiap bagiannya dan deskripsi tentang bentuk dan arransementnya dengan format orchestra.

Penelitian ini akan memberikan mafaat bagi penliti, bagi lingkungan akademik dan bagi masyarakat: Bagi penliti, yakni penelitian ini bermanfaat meningkatkan pengetahuan dan pemahaman peneliti tentang ilmu bentuk analisis. Bagi lingkungan akademik, penelitian ini bermanfaat meningkatkat pengetahuan dan pemahaman teori musik terutama dalam hal analisis bentuk dan struktur serta meningkatkan apresiasi karya musik dengan arrasement format orchestra. Bagi masyarakat, penelitian ini bermanfaat sebagai ilmu pengetahuan tentang bentuk lagu mars FKIP Universitas PGRI Palembang

Tinjauan Pustaka - penelitian ini seperti yang telas dijelaskan pada subbab sebelumnya bahwa lagu mars bermakna sebagai karya musik dengan ritme yang teratur dan beat dengan aksentuasi yang kuat. Ritme yang teratur dapat disamaartikan irama berturut-turut dengan tetap, sedangkan irama kuat bisa dipertegas dengan tekanan beat dalam suatu pola ritme yang diistilahkan dengan kata "Akzent". (Banoe, 2003 : 21). Senada yang dikemukahkan Mintargo tentang penjelasan lagu mars yakni lagu-lagu mars patriotic masa perang kemerdekaan digunakan mengiringi para pemuda pejuang yang dikirim bertempur ke garis depan dalam bentuk barisan dengan gerak langkah tegap mengikuti irama dengan penuh semangat. (Mintargo, 2008 : 5).

Pengertian kata Bentuk berdasarkan Kamus Besar Bahasa Indonesia yakni berarti wujud. Wujud dalam kesenian ada yang tampak dan dapat kita lihat seperti tari, lukis dan patung. Ada wujud yang tidak terlihat, akan tetapi bisa didengarkan, bisa diteliti dan dibahas struktur penyusunannya, seperti musik maupun nyanyian (Siswanto, 2017 : 77). Sedangkan pengertian bentuk pada musik menurut Jones yakni period: "Two related phrases, ending with a strong cadence; analogous to a sentence (regularly eight measure". Periode : Gabungan dua buah phrase, yang diakhiri dengan kadens yang kuat, dianalogkan dengan sebuah kalimat bahasa (biasanya terdiri dari 16 birama). (Jones, 1974 : 102). Sedangkan 
lagu memiliki arti nyanyian atau melodi pokok dalam karya musik. (Banoe, 2003 : 233).

Berdasarkan beberapa pendapat tentang pengertian bentuk dan lagu, maka bentuk lagu itu sendiri dapat disimpulkan yakni bagian dalam karya musik yang memiliki melodi pokok berserta lirik (nyanyian) yang berbentuk kalimat-kalimat musik (phrase) yang membentuk musik satu bagian. Hal ini dapat diperjelas bahwa bentuk lirik sangat mengikut bentuk musik, sedangkan bentuk musik terdiri dari phrase-phrase, bentuk arransement sangat mengikut pada bentuk musik, hal ini dikarenakan arransement mempertimbangkan harmoni dan orkestrasi pada lagu. Hal ini senada yang dikemukahkan oleh Jones yakni

“....analize this music, not only by following the melodic development of the themes, but also by simplifying the texture and discovering the underlying harmonic-tonal progressions". (Jones, 1974 : 276).

Jones menjelaskan dalam bukunya "music Theory" analisa musik ini, tidak hanya dengan mengikuti perkembangan melodi tema, tetapi juga dengan menyederhanakan tekstur dan menemukan progresi harmonik-tonal yang mendasarinya. Berdasarkan kutipan tersebut kata "tidak hanya" bisa dimaknai untuk mengalisis musik bisa melalui perkembangan pola melodi untuk menentukan kalimat musik dan perjalan progress kordnya (harmoni). Hal ini dipertegas oleh Aeron Coplan dalam Karyawanto yaitu Bentuk penelitian ini Analisis Musik. Menganalisis musik berarti menguraikan komponen-komponen pembentuk musik tersebut. Komponen di sini bisa diartikan sebagai unsur pembentuk musik. (Karyawanto, 2018 : 9).

Setelah penganalisisan musik (lagu mars FKIP Universitas PGRI Palembang), maka hasil analisis tersebut dideskripsikan berdasarkan urutan-urutan teknik analisis bentuk musik berdasarkan keilmuan musikologis. Berdasarkan beberapa konsep dan teori di atas maka penelitian ini memiliki tahapan-tahapan lapisan dalam kerangka konseptualnya yakni meliputi;

Lapisan ke-satu : lagu mars FKIP Universitas PGRI Palembang. Pada lapisan ini akan memuat tentang gambaran umum lagu tersebut.

Lapisan ke-dua : Bentuk lagu, bagian ke-dua ini akan membahas bentuk lagu mars FKIP Universitas PGRI Palembang, sebagai landasan konsep untuk analisis bentuk lirik, musik dan arransement.

Lapisan ke-tiga : Bentuk lirik, bentuk musik, bentuk arransement, pada bagian ini akan menjelaskan lapisan kedua sekaligus sebagai bagian analis bentuk musik yang akan dijelaskan satu persatu dalam bagiannya.

Lapis terakhir atau ke-empat yakni deskripsi dari lapis ke-satu, lapis ke-dua, dan lapis ke-tiga.

Adapun ke-empat lapisan tersebut apabila digambarkan seperti bagan berikut.

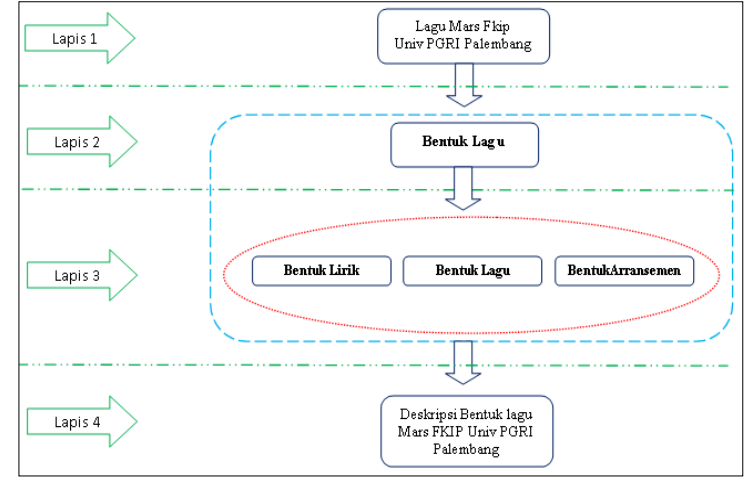

\section{Bagan 1. Kerangka berfikir/konseptual}

Metode Penelitian - Penelitian ini mencakup penelitian literature dengan melakukan kajian-kajian secara ilmiah untuk mendapatkan hasil jawaban atas pertanyaan pada rumusan masalah pada subbab sebelumnya. Sumber data yang didapat pada partitur lagu mars FKIP Universitas PGRI Palembang arsip program studi seni pertunjukan. Analisis data yakni mengacu pada keilmuan musikologi meliputi ilmu bentuk analisis bentuk musik, unsure-unsur musik, harmoni dan orkestrasi.

\section{Pembahasan}

\section{A. Lagu Mars FKIP Universitas PGRI Palembang}

Lagu Mars FKIP Universitas PGRI Palembang tercipta berdasarkan surat perintah tugas dekan FKIP universitas PGRI Palembang kepada bapak Silo Siswanto, M.Sn, pada tanggal 17 februari 2018, kemudian lagu tersebut selesai dibuat pada tanggal 27 juli 2018 dan di lounching bertepatan dengan yidisium FKIP Universitas PGRI Palembang di gedung Business Science Center universitas PGRI Palembang pada tanggal 31 juli 2018 yang dibawahkan oleh kelompok paduan suara Trust Choir FKIP Universitas PGRI Palembang.

Lagu Mars tersebut mendapatkan Piagam Penghargaan dari dekan FKIP Universitas PGRI Palembang atas kesuksesan dalam menciptakan lagu mars yang dimaksud. Awalnya lagu mars ini hanya terdiri dari dua suara yakni sopran dan tenor, kemudian lagu tersebut diarransemet oleh salah satu mahasiswi program studi seni pertunjukan yang bernama Annisya Anggraini menjadi empat suara yang terdiri dari suara Sopran, Alto, Tenor dan Bass (SATB).

Lagu Mars FKIP Universitas PGRI Palembang dinyanyikan oleh oleh kelompok paduan suara Trust Choir setiap acara yidisum di fakultas, dengan musik iringan yang di arransemet oleh sipencipta lagu mars ini dengan format orchestra, sehingga setiap lagu tersebut dinyanyikan diiringi musik minus one dengan audio orchestra.

Lagu mars FKIP Universitas PGRI yang dimainkan pada tangganada Bes mayor atau Bes = Do dengan tanda birama 4/4 dan tempo moderato. Lagu ini memiliki 3 bagian musik dan 3 kelompok bait pada liriknya. 


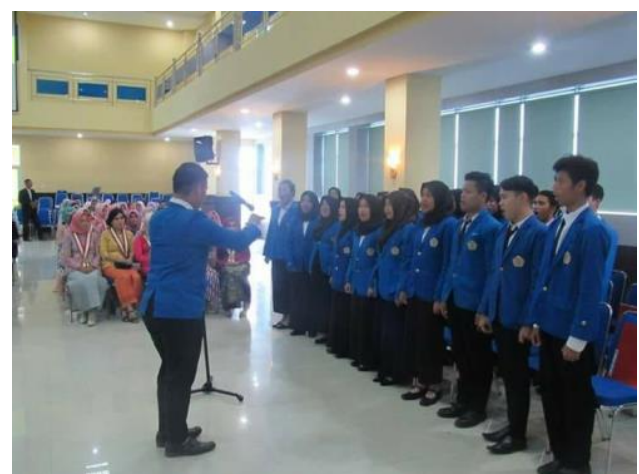

Gambar1. Menyanyikan lagu Mars FKIP Universitas PGRI Palembang (Dokumen Arsip Trust Choir)

B. Analisis Bentuk lagu

Lagu mars FKIP Universitas PGRI Palembang terdiri dari 3 bagian (periode). Setiap Period atau bagian memiliki frase tanya yang disebut antecedent dan frase jawab disebut consequent. Untuk penyimbolan analisis perbagian dalam bentuk lagu, Periode atau bentuk satu bagian dalam lagu disimbolkan dengan huruf capital " $A$ " atau "B", dan "C". sedangkan untuk penyimbolan frase pada lagu dengan huruf kecil "a" atau "b" dan seterusnya.

Lagu mars FKIP Universitas PGRI Palembang memiliki 26 birama, dengan 3 bagian yakni "A", "B" dan "C" akan tetapi dalam lagu tersebut terdapat repetisi atau pengulangan lagu yang utuh sehingga lagu tersebut memiliki period A,B,C A,B,C

Berikut bentuk lagu mars FKIP Universitas PGRI Palembang akan dicontohkan ke dalam bagan sebagai berikut

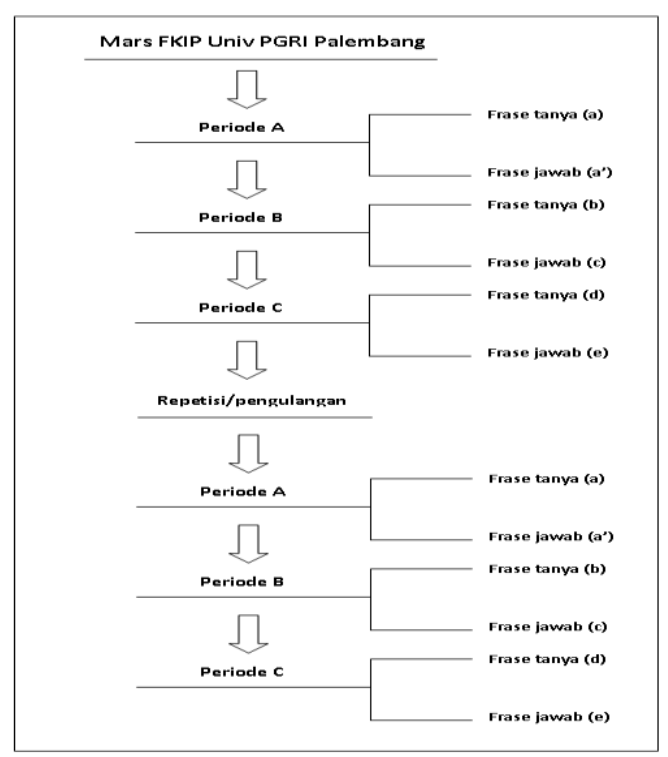

Bagan 2. Bentuk lagu Mars FKIP UNIV PGRI Palembang

Berdasarkan bagan 2 di atas, periode A terdiri dari frase a dan frase b. Periode A memiliki sebanyak 14 birama terdiri; dari frase a 4 birama dan frase a' 4 berima. Sedangkan Periode B terdiri dari frase $b$ dan frase c dengan memiliki sebanyak 5 birama yakni; frase b 4 birama dan frase c 5 birama. Periode C memiliki 9 birama yang terdiri dari frase d 4 birama dan frase e 5 birama. Sehingga total jumlah birama pada lagu mars FKIP Universitas PGRI Palembang 26 birama.

Apabila bentuk lagu mars tersebut diuraikan berdasarkan bagan di atas maka potongan-potongan melodi dalam frase dapat dilihat seperti notasi di bawah ini.

\section{Periode A} frase tanya a

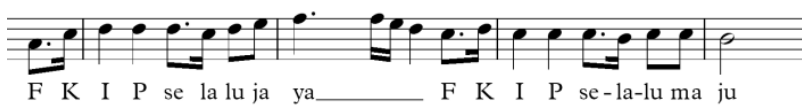

frase tanya a'

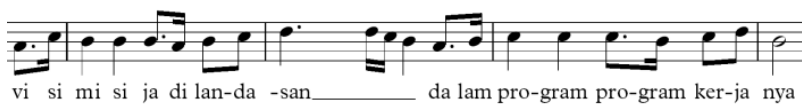

Notasi 1. Periode A

Periode A memiliki 1 bait liriknya yakni 1 bait tersebut terdapat 4 baris lirik, dimana baris ke-1 dan ke-2 terletak pada frase tanya, sedangkan baris ke-3 dan ke-4 terletak pada frase jawab. Kedua frase tersebut memiliki motif yang sama hanya saja perbedaanya terletak pada melodi atau tinggi rendah bunyinya. Sehingga frase tanya mendapatkan simbol a dan frase jawab mendapatkan simbol a'.

Perdiode B
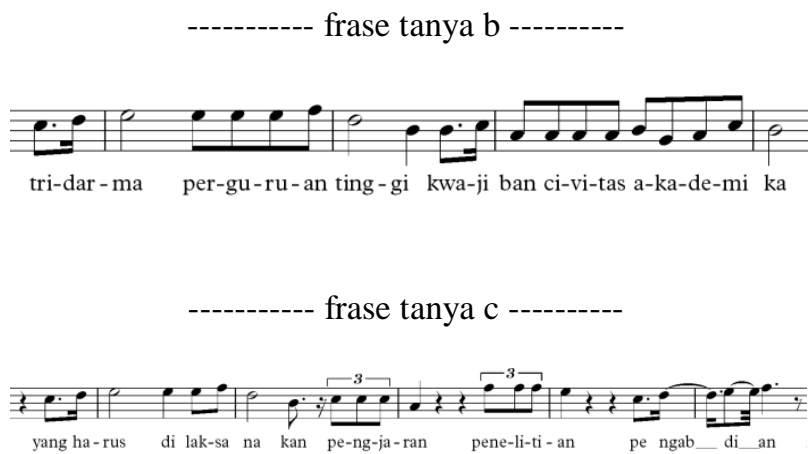

Notasi 2. Periode B

Periode B memiliki 1 bait atau 4 baris lirik, dimana baris ke-1 dan ke-2 terletak pada frase tanya, sedangkan baris ke-3 dan ke-4 terletak pada frase jawab. Kedua frase tersebut memiliki motif yang berbeda. Sehingga frase tanya mendapatkan simbol $b$ dan frase jawab mendapatkan simbol c'. 
Perdiode C frase tanya d -----------

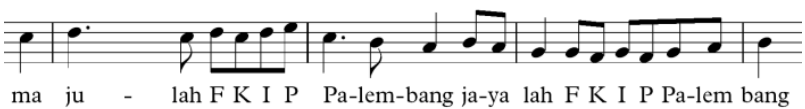

ja-ya lah F K I P Pa-lem bang

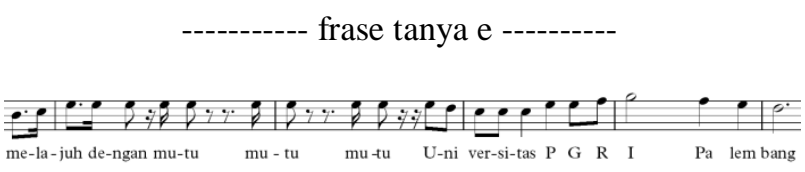

Notasi 3. Periode C

Periode $\mathrm{C}$ memiliki 1 bait atau 4 baris lirik, dimana baris ke-1 dan ke-2 terletak pada frase tanya, sedangkan baris ke-3 dan ke-4 terletak pada frase jawab. Kedua frase tersebut memiliki motif yang berbeda. Sehingga frase tanya mendapatkan simbol d dan frase jawab mendapatkan simbol e.

\section{Analisis Bentuk lirik}

Bentuk lirik pada lagu mars FIKP universitas PGRI Palembang, mengikut pada bentuk lagu dalam frasenya. Frase adalah kalimat musik. Dapat dianalogikan bahwa bentuk lirik bisa dilihat dari bentuk musik begitu juga sebalik. Hal ini tersebut akan di ilustrasikan seperti contoh gambar di bawah,

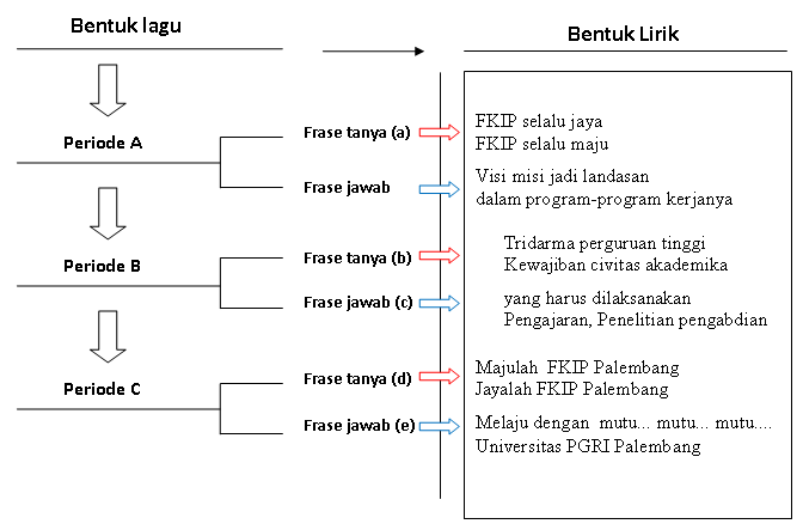

Bagan 3. Bentuk lagu (musik dan lirik)

Bagan 3. menunjukkan bahwa bentuk lagu mas FKIP Universitas PGRI Palembang dapat dilihat dari dua kriteria yakni bentuk musik dan bentuk lirik perbait. Hal ini menegaskan bahwa penggarapan lagu tersebut dua aspek yakni lirik dan kalimat musik sangat dipertimbangkan hal ini dimaksudkan agar terjalin harmoni yang dalam artian luas. Seperti penjelasan Langer dalam Tulisannya Bentuk musik secara umum dibingkai oleh kerangka musikal sebagaimana halnya kerangka bagi makhluk hidup sehingga sangat besar peranannya bagi suatu karya musik. Sedangkan mengenai 'bentuk' sendiri didefinisikan sebagai struktur, artikulasi, sebuah hasil kesatuan menyeluruh dari suatu hubungan berbagai faktor yang saling bergayutan atau lebih tepatnya suatu cara di mana keseluruhan aspek bisa dirakit. Langer dalam (Siswanto, $2017: 81$ ).

Berikut naskah lirik mars FKIP Universitas PGRI Palembang seperti contoh gambar di bawah ini

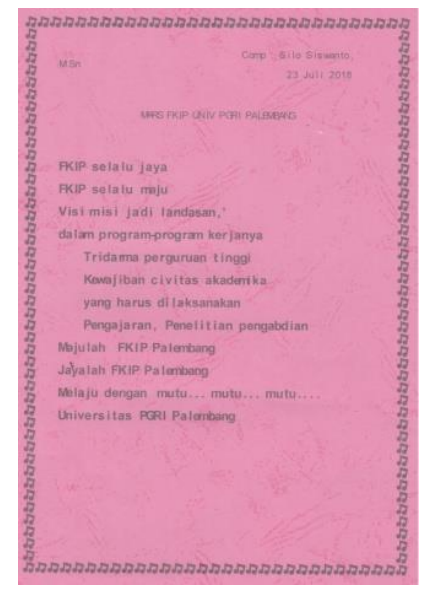

Gambar 2. Lirik lagu Mars FKIP Univ. PGRI Palembang (Dokumen Arsip Trust Choir)

\section{Analisis Bentuk Arrasamen}

Bagian analisis bentuk arransemen pada subbab ini perlu ditegaskan bahwa yang akan peneliti bahas bentuk arransemet dengan format orchestra. Karena hal tersebut sangat mempengaruhi bentuk lagu secara keseluruhan, misalnya salah satu contoh perbedaannya lagu mars yang belum memiliki musik irinngan dan sudah memiliki musik iringan yakni ada pada perbedaan biramanya, lagu mars FKIP sebelum memiliki musik iringan memiliki 26 birama, kemudian ada repetisi ke awal lagi hingga menjadi 42 birama, kemudian setelah lagu tersebut memiliki musik iringan yang sudah di arransemen maka semuanya menjadi 72 birama, karena musik tersebut sudah memiliki bentuk musik yang komplit diantaranya sudah memiliki intro kemudian lagu, interlude, kemudian repetisi masuk lagu terakhir coda. Selain dari itu, musik iringannya selain diperuntukkan pembentuk harmoni lagu melainkan sebagai penguat beat tekanan pada lagu mars, sehingga lagu tersebut benar-benar dapat menghasilkan aksen gerak langkah tegap mengikuti irama dengan penuh semangat. (Mintargo, 2008, hal. 5).

Adapun instrument musik yang ada pada lagu mars tersebut meliputi vocal; sopran, alto, tenor dan bass. Instrument tiup; flute, horn in $\mathrm{F}$ dan trombone. Piano instrument petik gitar akustik. Instrument gesek; violin I, violin II, viola, violin cello dan contrabass, Perkusi; cymbals, triangle, snare drum dan timpani. Semua itu berjumlah 18 instrumen. Dengan bentuk musik terdiri dari intro ; dari birama 1-7, lagu bagian $\mathrm{ABC}$ dari birama 7-33, interlude dari birama 34-46, repetisi lagu $\mathrm{ABC}$ dari birama 46-72, terkahir coda di birama 72. Analisis bentuk musik lagu mars yang sudah memiliki musik iringan tersebut apabila dibuatkan bagannya seperti contoh di bawah ini. 


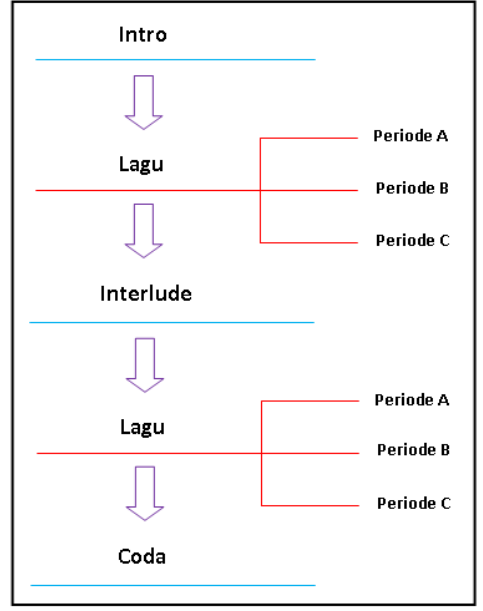

\section{Bagan 4. Struk lagu mars FKIP}

Berdasarkan bagan 4 di atas, dapat diperjelas bahwa lagu mars FKIP Universitas PGRI Palembang memiliki bentuk musik dengan pengembangan musik iringannya, misalnya intro, menghadirkan harmoni yang tegas dan khidmat sebagai opening awal untuk masuk lagu, setelah masuk lagu kemudian interlude, pada bagian interlude hanya gitar saja yang main pada bagian ini, hal ini hanya ining menampilkan suara dengan petikan gitar tunggal khas musik daerah provinsi Sumatera-Selatan. Adapun potongan melodi intro dan interlude seperti contoh notasi di bawah ini.

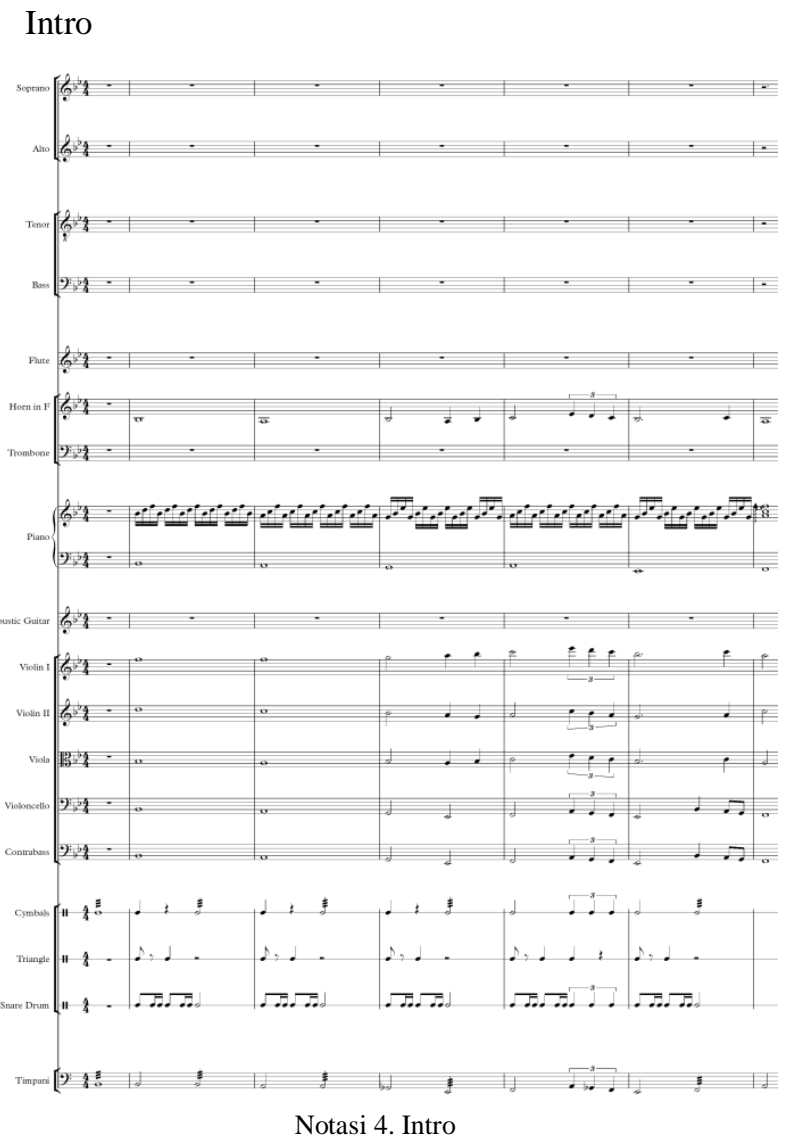

Bagian intro dalam arransemen ini, yang membawakan melodic background yakni alat musik piano, sedangkan pada alat musik yang lainnya membawakan beat dan harmonic background.

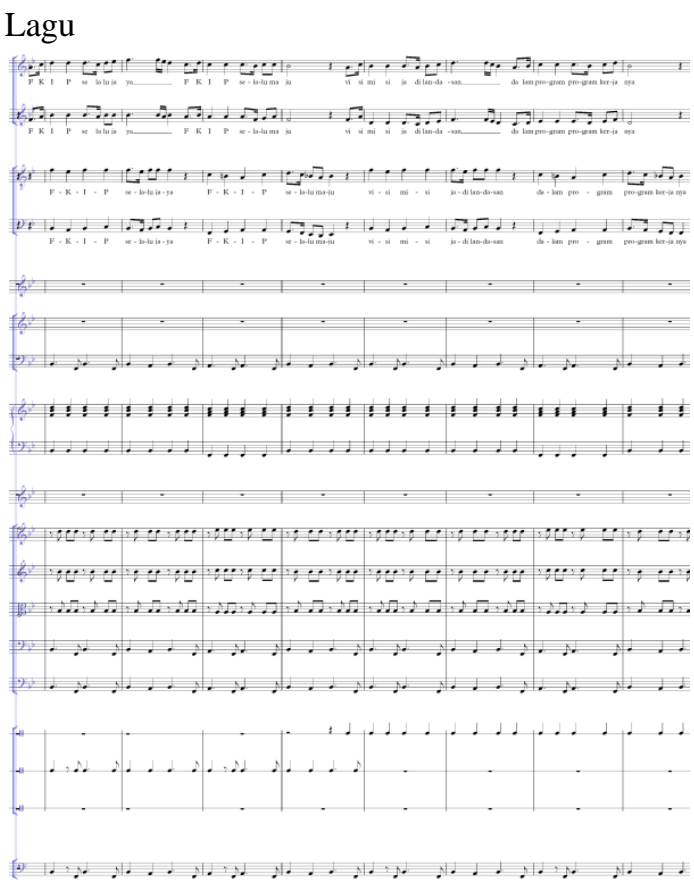

Notasi 5. Lagu

Notasi lagu mars FKIP Universitas PGRI Palembang instrumen pengiringnya memainkan harmonik background serta membentuk progess kor akhir frase dalam pembentukan cades

\section{Interlude}

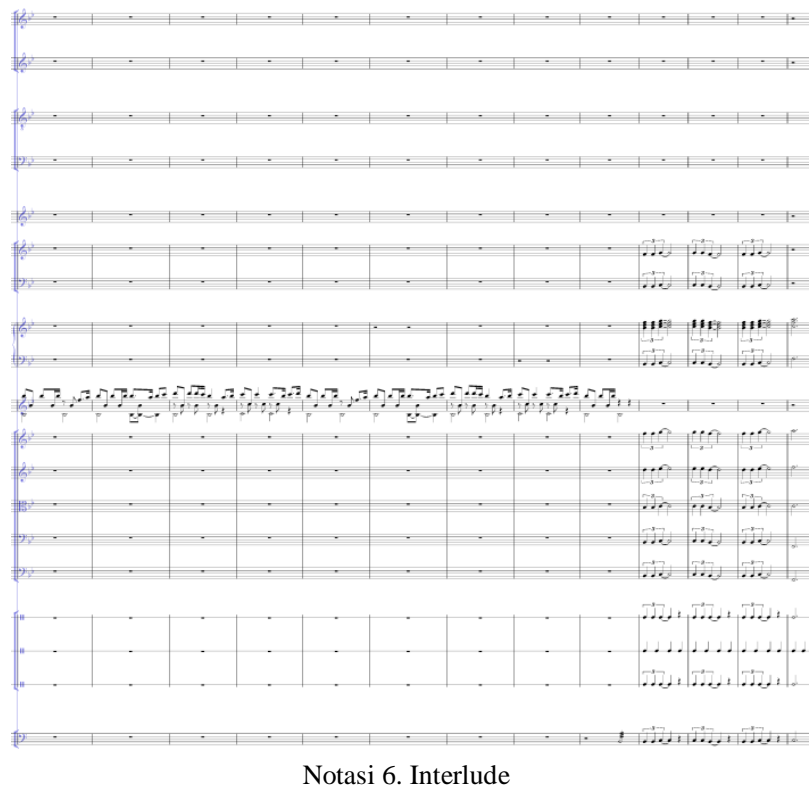

Pada bagian interlude dari birama 34-42 dibawakan oleh permainan gitar tunggal, hal ini dimaksudkan oleh aranger sekaligus komposer pada lagu ini, hendak menghadirkan nuansa petikan gitar tunggal batang hari sembilan sebagai musik daerah Sumatera-Selatan. 
Dengan harapan nilai-nilai kearifan lokal bisa tertuang ke dalam lagu mars FKIP Universetas PGRI Palembang tersebut.

\section{Kesimpulan}

Penelitian ini menggunakan berbagai konsep diantaranya "musikologi" untuk membeda Analisis bentuk dan struktur mars FKIP Univesitas PGRI Palembang yang akan diuraikan berupa penggalan partisi pada notasi untuk dideskripsikan.

Lagu mars FKIP memiliki bentuk musik poli metrik dimana frase antecedent dan frase consequent tidak memiliki jumlah birama yang sama misalnya periode $\mathrm{C}$ memiliki 9 birama yang terdiri dari frase d 4 birama dan frase e 5 birama.

Arrasemen lagu mars FKIP Universitas Palembang dengan format orchestra bertujuan untuk mendapatkan beat yang kuat dengan aksentuasi yang semangat, energi dan khidmat agar lagu mars tersebut dirasakan secara musikalitas tercapai yakni lagu mars adalah lagu patriotic lagu perjuangan.

\section{Saran}

Hasil penelitian hendaknya menjadi materi dalam penyusunan materi ajar yang berhubungan dengan ilmu bentuk analisis musik khususnya prodi seni pertunjukan FKIP Universitas PGRI Palembang. selain ilmu bentuk analisis musik juga membahas dalam hal orkestrasi dengan format orchestra.

Hendaknya musik iringan lagu Mars FKIP Universitas PGRI Palembang dibawakkan dengan musik hidup bukan menggunakan minus one, karena kalau menggunakan musik minus one dinamika tidak begitu terasa dan symbol-simbol agak seperti ekspresi tidak bisa dinyanyikan mengingat musik minus one adalah musik robot atau musik yang temponya tidak bisa di rubahrubah meskipun ada simbol-simbol tertentu menyertainya. Akhirnya, semoga penelitian ini menjadi pengetahuan tentang ilmu analisis musik tanpa harus mengalisis musik klasik.

\section{Daftar Pustaka}

Banoe, P. (2003). KAMUS MUSIK. Yogyakarta: Kanisius.

Jones, G. (1974). MUSIC THEORY. New York:

Barnes dan Noble Book.

Karyawanto, H. Y. (2018). BENTUK LAGU DAN

AMBITUS NADA PADA ORKESTRASI

MARS UNESA. VIRTUOSO (Jurnal

Pengkajian Dan Penciptaan Musik) , 1 (1), 8 14.

Mintargo, W. (2008). Musik Revolusi Indonesia.

Yogyakarta: Perpustakaan Nasional: dalam katalog terbitan (KDT).

Siswanto, S. (2017). Bentuk dan Struktur Musik Pertunjukan Rejung. SITAKARA, 76. 